\title{
Synthesis, Tunable Multicolor Output, and High Pure Red Upconversion Emission of Lanthanide-Doped $\mathrm{Lu}_{2} \mathrm{O}_{3}$ Nanosheets
}

\author{
Lingzhen Yin, Tianmei Zeng, Zhigao Yi, Chao Qian, and Hongrong Liu \\ College of Physics and Information Science and Key Laboratory of Low-Dimensional Quantum Structures and Quantum Control of \\ the Ministry of Education, Hunan Normal University, Changsha, Hunan 410081, China
}

Correspondence should be addressed to Hongrong Liu; hrliu@hunnu.edu.cn

Received 9 October 2013; Accepted 22 November 2013

Academic Editor: Jianhua Hao

Copyright (C) 2013 Lingzhen Yin et al. This is an open access article distributed under the Creative Commons Attribution License, which permits unrestricted use, distribution, and reproduction in any medium, provided the original work is properly cited.

$\mathrm{Yb}^{3+}$ and $\mathrm{Ln}^{3+}(\mathrm{Ln}=\mathrm{Er}, \mathrm{Ho})$ codoped $\mathrm{Lu}_{2} \mathrm{O}_{3}$ square nanocubic sheets were successfully synthesized via a facile hydrothermal method followed by a subsequent dehydration process. The crystal phase, morphology, and composition of hydroxide precursors and target oxides were characterized by X-ray diffraction (XRD), field emission scanning electron microscope (FE-SEM), and energy-dispersive X-ray spectroscope (EDS). Results present the as-prepared $\mathrm{Lu}_{2} \mathrm{O}_{3}$ crystallized in cubic phase, and the monodispersed square nanosheets were maintained both in hydroxide and oxides. Moreover, under $980 \mathrm{~nm}$ laser diode (LD) excitation, multicolor output from red to yellow was realized by codoped different lanthanide ions in $\mathrm{Lu}_{2} \mathrm{O}_{3}$. It is noteworthy that high pure strong red upconversion emission with red to green ratio of 443.3 of Er-containing nanocrystals was obtained, which is beneficial for in vivo optical bioimaging.

\section{Introduction}

In the past few decades, lanthanide-doped upconversion phosphors have received considerable attention due to their application in display systems [1], optical processing sensors [2], solid-state lasers [3], fluorescent detection, and label of biomolecules [4]. More importantly, as the applications in biological assays and medical imaging, the conventional semiconductor quantum dots were limited due to cytotoxicity, photobleaching, photodamage and low signal-to-noise ratio for excitation with short wavelength (usually ultraviolet and visible light) $[5,6]$. Upconversion nanocrystals (UCNCs), which overcome those problems and absorb long wavelength (usually near infrared (NIR) light) and emit short wavelength, were believed to be a new kind of fluorescence materials $[7,8]$. Besides, UCNCs have low radiation damage, chemical stability, and deep penetration of NIR excitation source compared with conventional fluorescent materials $[9,10]$.

It is well known that the luminescence property of UCNCs is affected by a combination of different host/activator, doping concentrations, nanocrystal size, shape, and the coatings [11-13]. Therefore, it is important to select appropriate host matrixes for achieving excellent luminescence property. Lutetium oxides are one of the excellent host matrix for ionizing radiation detection and X-ray phosphors because of their unique properties: high atomic number of $\mathrm{Lu}$ (71) and high density $\left(9.42 \mathrm{~g} / \mathrm{cm}^{-3}\right)[14,15]$. Besides, the ionic radius of $\mathrm{Lu}^{3+}(1.117 \AA)$ is closer to the radius of $\mathrm{Yb}^{3+}(1.125 \AA)$ than that of other lanthanide ions [16], which may improve the stability of UCNCs while doping high concentration $\mathrm{Yb}^{3+}$. More importantly, the energy levels of Lu, especially the $4 \mathrm{f}$ orbital, make Lu-containing structure of stronger luminescence intensity than Y-containing crystal [17-19], which was known as very efficient phosphors.

As a potential host matrix, lutetium oxides have received many research interests. Studies on the synthesis of $\mathrm{Lu}_{2} \mathrm{O}_{3}$ with controlled size and various morphologies have been extensively carried out [20-22]. In addition, the luminescence properties of Lu-containing nanocrystals, for example, multicolor output manipulation by changing the reaction temperature, doping different lanthanide ions, and tuning the concentration of sensitizer or activator ions, have been widely investigated [23-25]. However, most of those researches are about lutetium fluorides, and the study on lanthanide ionsdoped $\mathrm{Lu}_{2} \mathrm{O}_{3}$ was still limited. Furthermore, the lutetium oxide nanocubic sheets have rarely been mentioned. 
Herein, we have prepared $\mathrm{Yb}^{3+}, \mathrm{Ln}^{3+}(\mathrm{Ln}=\mathrm{Er}, \mathrm{Ho})$ codoped $\mathrm{Lu}_{2} \mathrm{O}_{3}$ via a simple and green hydrothermal method followed by a dehydration process [26]. Moreover, under the excitation of $980 \mathrm{~nm}$ laser diode, strong eye-visible red and yellow lights were observed. And the mechanism of the pure red upconversion emission was discussed in detail.

\section{Experimental Section}

Rare earth nitrates $\mathrm{RE}\left(\mathrm{NO}_{3}\right)_{3} \cdot 6 \mathrm{H}_{2} \mathrm{O}(\mathrm{RE}=\mathrm{Lu}, \mathrm{Yb}, \mathrm{Er}, \mathrm{Ho}$, 99.99\%) were purchased from Sinopharm Chemical Reagent Co., Ltd (China). All other materials are of analytical grade and used directly without further purification.

2.1. Sample Preparation. $\mathrm{Yb}^{3+}$ and $\mathrm{Ln}^{3+}(\mathrm{Ln}=\mathrm{Er}, \mathrm{Ho})$ codoped $\mathrm{Lu}_{2} \mathrm{O}_{3}$ with a composition of $\mathrm{Lu}_{1.60-x} \mathrm{Yb}_{0.40} \mathrm{Ln}_{x} \mathrm{O}_{3}$ $(x=0.04)$ was prepared by using a facile hydrothermal method followed by a dehydration process [26]. As for the synthesis of $\mathrm{Lu}_{2} \mathrm{O}_{3}: \mathrm{Yb}^{3+}, \mathrm{Er}^{3+}$, the corresponding amount of rare earth nitrate (total amount: $1 \mathrm{mmol}$ ) was thoroughly mixed with $20 \mathrm{~mL}$ distilled water, then $\mathrm{NaOH}$ solution with $\left[\mathrm{OH}^{-}\right]=5 \mathrm{~mol} / \mathrm{L}$ was gradually added to obtain the hydroxide precipitates and adjust the $\mathrm{pH}$ to 14 under strong stirring. After being stirred 10 mins, the mixed solution was transferred into autoclaves to carry out a hydrothermal treatment at $180^{\circ} \mathrm{C}$ for about $12 \mathrm{~h}$, and after cooling down to room temperature the hydroxide precursor was purified by centrifugation, washed with distilled water several times, and then dried at $80^{\circ} \mathrm{C}$. At last, the corresponding rare earth-doped oxides were prepared successfully through the subsequent dehydration at $800^{\circ} \mathrm{C}$ for about 4 hours. The $\mathrm{Yb} / \mathrm{Ho}$ codoped $\mathrm{Lu}_{2} \mathrm{O}_{3}$ was prepared in a similar procedure.

2.2. Characterization. Power X-ray diffraction (XRD) patterns of the samples were measured with $\mathrm{D} / \max 2500 / \mathrm{PC}$ diffractometer using $\mathrm{Cu}-\mathrm{K} \alpha$ radiation $(\lambda=1.5406 \AA)$ at $40 \mathrm{kV}$ and $250 \mathrm{~mA}$. The morphology and composition of the samples were recorded on a FE-SEM equipped by an EDS system (FEI NanoSEM 450). The upconversion spectra were recorded using R-500 spectrophotometer under an unfocused $980 \mathrm{~nm}$ LD excitation at room temperature, and the corresponding digital photographs were taken by a digital camera under $980 \mathrm{~nm}$ infrared irradiation.

\section{Results and Discussion}

3.1. Phase and Morphology. Figure 1 shows the XRD patterns of $\mathrm{Lu}_{2} \mathrm{O}_{3}: \mathrm{Yb}^{3+}, \mathrm{Ho}^{3+}$ and the standard cubic phase $\mathrm{Lu}_{2} \mathrm{O}_{3}$ (JCPDS no. 86-2475) for comparison. As demonstrated, all diffraction peaks of $\mathrm{Yb}-\mathrm{Ho}$ codoped $\mathrm{Lu}_{2} \mathrm{O}_{3}$ are perfectly indexed to the pure cubic phase $\mathrm{Lu}_{2} \mathrm{O}_{3}$ and no other impurity peaks are detected, implying the high purity cubic phase structure is obtained via the facile hydrothermal approach. Moreover, compared with the standard diffraction peaks, there are very little deviations because the radius of main doped ion $\mathrm{Yb}^{3+}(1.125 \AA)$ is very close to that of $\mathrm{Lu}^{3+}(1.117 \AA)$ [16].

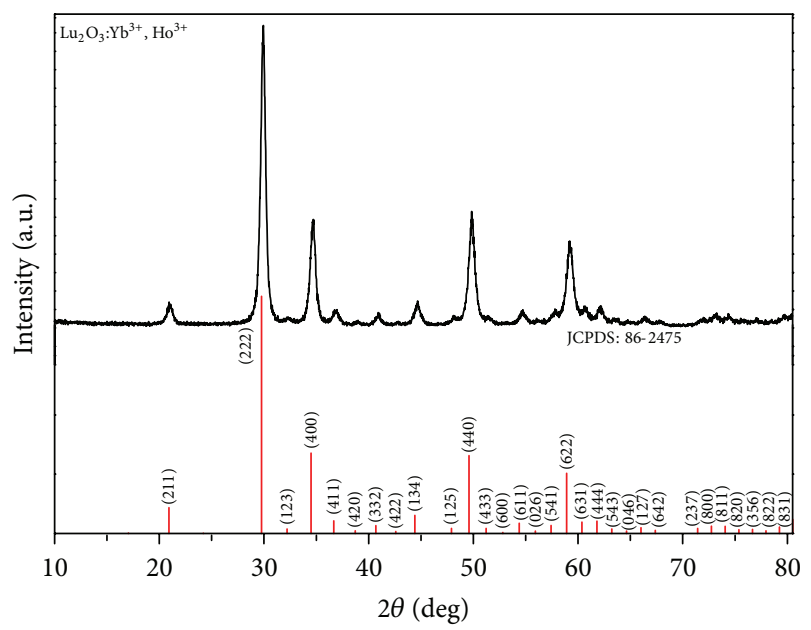

FIGURE 1: XRD patterns of $\mathrm{Yb}^{3+}$ and $\mathrm{Ho}^{3+}$ codoped $\mathrm{Lu}_{2} \mathrm{O}_{3}$ powder obtained via a hydrothermal approach (black line); the red lines indicate the standard data of pure cubic $\mathrm{Lu}_{2} \mathrm{O}_{3}$ structure (JCPDS: 86-2475).

More information about morphology and composition can be obtained by FE-SEM observation and EDS analysis. Figure 2 shows the FE-SEM images of precursor $\mathrm{Lu}(\mathrm{OH})_{3}$ (Figures 2(a) and 2(b)) and $\mathrm{Lu}_{2} \mathrm{O}_{3}: \mathrm{Yb}^{3+}, \mathrm{Ho}^{3+}$ (Figures 2(c) and $2(\mathrm{~d})$ ). As shown in FE-SEM images, all of these two samples present square nanosheets structure and no obvious difference between the two samples in the morphology is founded, implying the samples have well thermal stability. The corresponding EDS (Figure 2(e)) shows the main elements components are $\mathrm{Lu}, \mathrm{O}, \mathrm{Yb}$, and $\mathrm{Ho}$, implying the $\mathrm{Yb}$ and Ho ions are doped into the host matrix successfully.

3.2. Upconversion Luminescent Properties. Figure 3(a) demonstrates the upconversion luminescence spectra of $\mathrm{Yb}$ Er codoped $\mathrm{Lu}_{2} \mathrm{O}_{3}$ nanocrystals. Under the excitation of $980 \mathrm{~nm}$ laser diode, an intense red emission band centered at $655 \mathrm{~nm}$ and a very weaker green emission area are observed. After magnifying 350 times (left inset in Figure 3(a)), the green emission area includes two weak bands centered at $526 \mathrm{~nm}$ and $542 \mathrm{~nm}$, respectively. Moreover, the red to green $(\mathrm{R} / \mathrm{G})$ ratio is measured to a very large value of 443.3, resulting in a pure red upconversion emission, which is also verified by the digital photograph (right inset of Figure 3(a)) and CIE chromaticity coordinates $(X=0.6312, Y=$ 0.33346) illustrated in Figure 3(b). When codoped Yb-Ho ions to $\mathrm{Lu}_{2} \mathrm{O}_{3}$ nanocrystals, the as-prepared structure has both intense green and red emissions (Figure 3(c)). Therefore, bright eye-visible yellow light was observed (inset of Figures $3(\mathrm{c})$ and 3(d)), differing from the red light seen from the YbEr codoped samples. Therefore, the multicolor tuning from red to yellow can be achieved by simply doping different activator ions such as $\mathrm{Er}^{3+}$ and $\mathrm{Ho}^{3+}$. More importantly, the pure red upconversion emission with large $\mathrm{R} / \mathrm{G}$ ratio of 443.3 was realized, which is more beneficial for optical bioimaging for deep tissue penetration. 


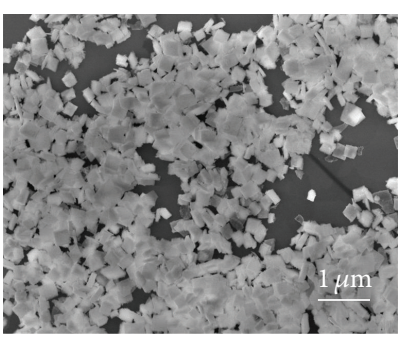

(a)

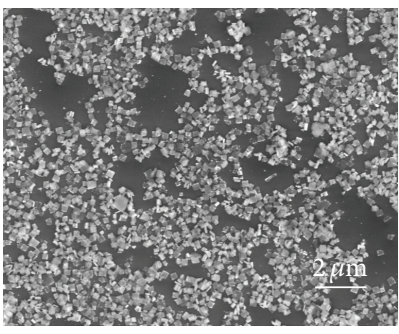

(c)

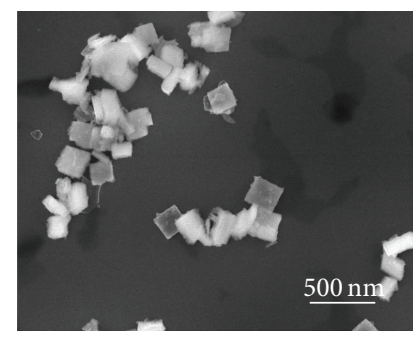

(b)

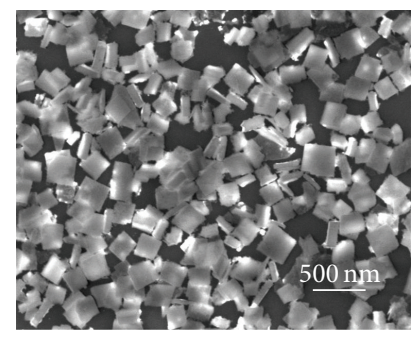

(d)

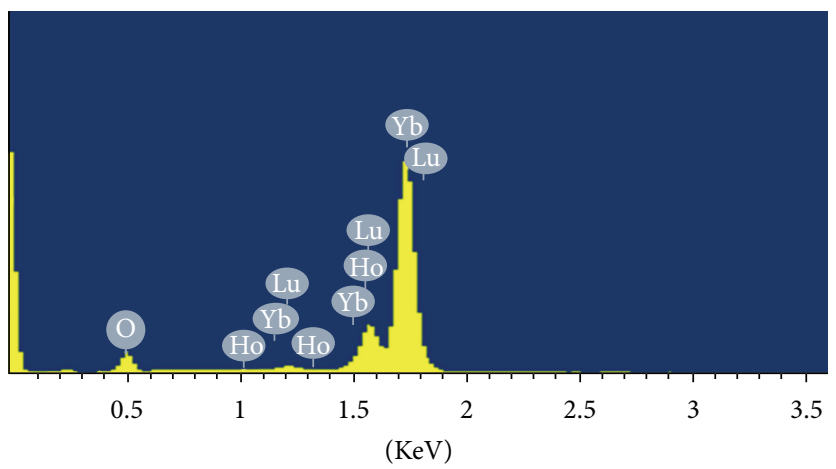

(e)

FIGURE 2: FE-SEM images of the as-prepared precursor $\mathrm{Lu}(\mathrm{OH})_{3}: \mathrm{Yb}^{3+}, \mathrm{Ho}^{3+}$ : (a) low magnification, (b) high magnification and obtained FE-SEM images of target $\mathrm{Lu}_{2} \mathrm{O}_{3}: \mathrm{Yb}^{3+}, \mathrm{Ho}^{3+}$, (c) low magnification, (d) high magnification, and (e) EDS of the obtained $\mathrm{Lu}_{2} \mathrm{O}_{3}: \mathrm{Yb}^{3+}, \mathrm{Ho}^{3+}$ nanocubic sheets.

To reveal the possible upconversion mechanism, a simplified energy level diagram with indicated pathways is presented (Figure 4). As shown, the two weak green emissions of Yb-Er co-doped samples are assigned to the ${ }^{2} \mathrm{H}_{11 / 2} \rightarrow{ }^{4} \mathrm{I}_{15 / 2}$ $(526 \mathrm{~nm})$ and ${ }^{4} \mathrm{~S}_{3 / 2} \rightarrow{ }^{4} \mathrm{I}_{15 / 2}(542 \mathrm{~nm})$ transitions of $\mathrm{Er}^{3+}$, and the red emission is attributed to the ${ }^{4} \mathrm{~F}_{9 / 2} \rightarrow{ }^{4} \mathrm{I}_{15 / 2}$ transition of $\mathrm{Er}^{3+}$. The high intensity ratio of the red to green emission can be explained from Figure 4. One reason of the red emission enhancement is that energy transfer from sensitizer ion $\mathrm{Yb}^{3+}$ at ${ }^{2} \mathrm{~F}_{5 / 2}$ state to activator ion $\mathrm{Er}^{3+}$ through ${ }^{4} \mathrm{I}_{15 / 2} \rightarrow{ }^{4} \mathrm{I}_{11 / 2}$ transition, and then perform a nonradiative decay, which increase the number of $\mathrm{Er}^{3+}$ at ${ }^{4} \mathrm{I}_{13 / 2}$ level, at last, energy transfer from $\mathrm{Yb}^{3+}$ at ${ }^{2} \mathrm{~F}_{5 / 2}$ state to $\mathrm{Er}^{3+}$ through ${ }^{4} \mathrm{I}_{13 / 2} \rightarrow{ }^{2} \mathrm{~F}_{9 / 2}$. Another reason is the efficient cross-relaxation (CR) process of $\mathrm{Er}^{3+}:{ }^{4} \mathrm{I}_{11 / 2}+{ }^{4} \mathrm{~F}_{7 / 2} \rightarrow{ }^{4} \mathrm{~F}_{9 / 2}+{ }^{4} \mathrm{~F}_{9 / 2}$ illustrated in Figure 4. The CR process strengthens the red band and weakens the green emission because most of the ions at
${ }^{4} \mathrm{~F}_{7 / 2}$ state transfer to ${ }^{4} \mathrm{~F}_{9 / 2}$ directly bypassing the ${ }^{2} \mathrm{H}_{11 / 2}$ and ${ }^{4} \mathrm{~S}_{3 / 2}$, which contribute to the green emission [23-25].

On the other hand, the green and red upconversion emissions of Ho containing sample are mainly attributed to the transitions ${ }^{5} \mathrm{~F}_{4} \rightarrow{ }^{5} \mathrm{I}_{8} \quad(541 \mathrm{~nm}),{ }^{5} \mathrm{~S}_{2} \rightarrow{ }^{5} \mathrm{I}_{8}$ $(551 \mathrm{~nm}),{ }^{5} \mathrm{~F}_{5} \rightarrow{ }^{5} \mathrm{I}_{8}(640-678 \mathrm{~nm})$ of $\mathrm{Ho}^{3+}$ (Figure 4). As illustrated in Figure 4, all the processes need two-photo energy transfer; the red emission state ${ }^{5} \mathrm{~F}_{5}$ is attributed to phonon-assisted energy transfer: ${ }^{5} \mathrm{I}_{7}\left(\mathrm{Ho}^{3+}\right) \rightarrow{ }^{5} \mathrm{~F}_{5}\left(\mathrm{Ho}^{3+}\right)$ and non-radiative decay from ${ }^{5} \mathrm{~S}_{2}$. When doping high concentration $\mathrm{Yb}^{3+}(20 \%)$, all the three emissions are enhanced and lead to an intense eye-visible yellow light with CIE chromaticity coordinates at $X=0.419, Y=0.5318$.

\section{Conclusion}

In summary, monodispersed $\mathrm{Lu}_{2} \mathrm{O}_{3}$ co-doped with $\mathrm{Yb}^{3+}$ and $\operatorname{Ln}^{3+}(\mathrm{Ln}=\mathrm{Er}$, Ho) square nanocubic sheets were successfully fabricated with a simple hydrothermal method. 


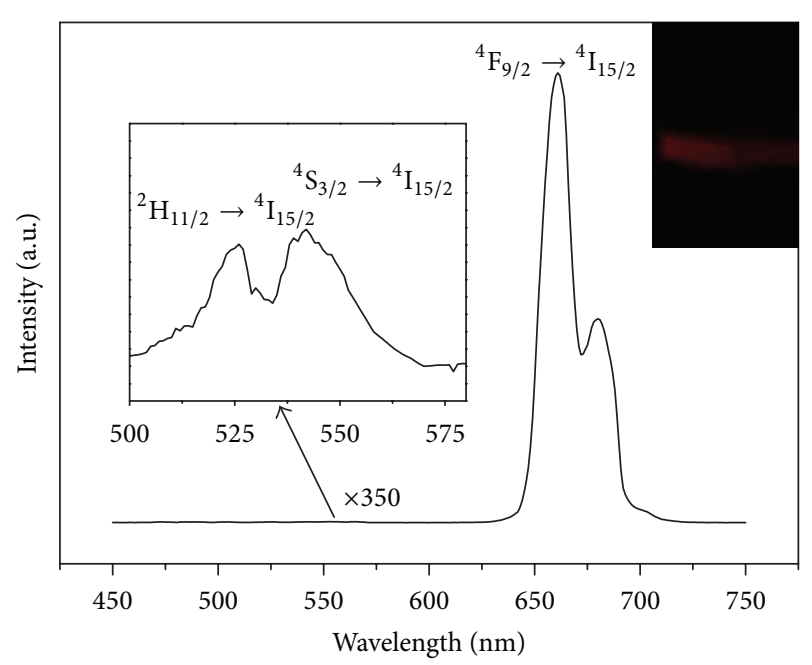

(a)

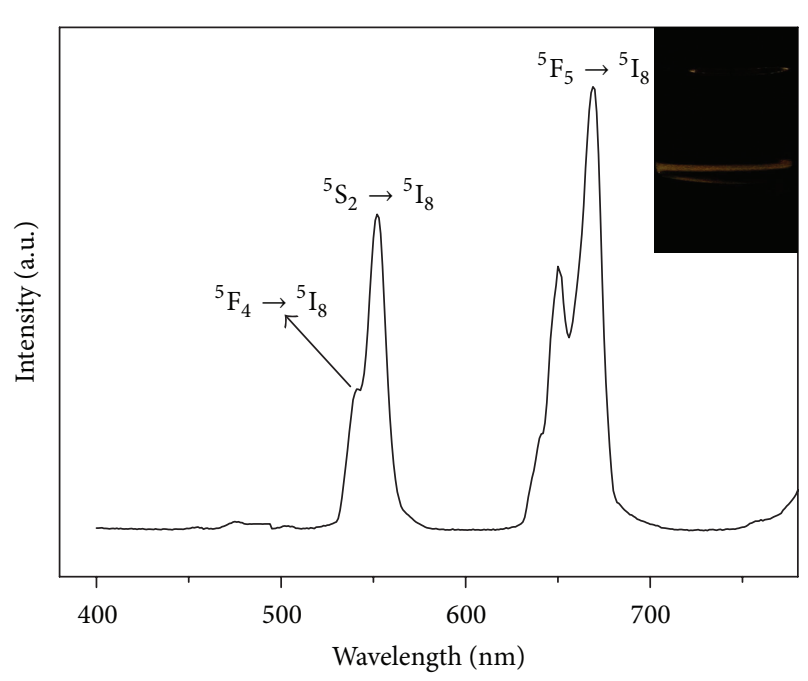

(c)

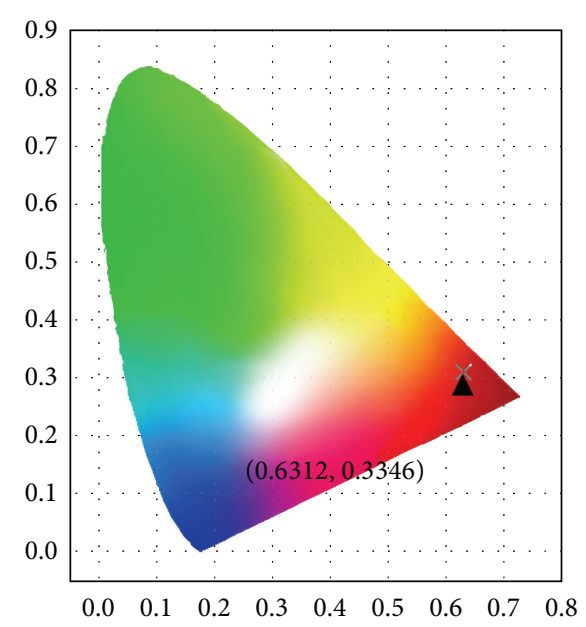

(b)

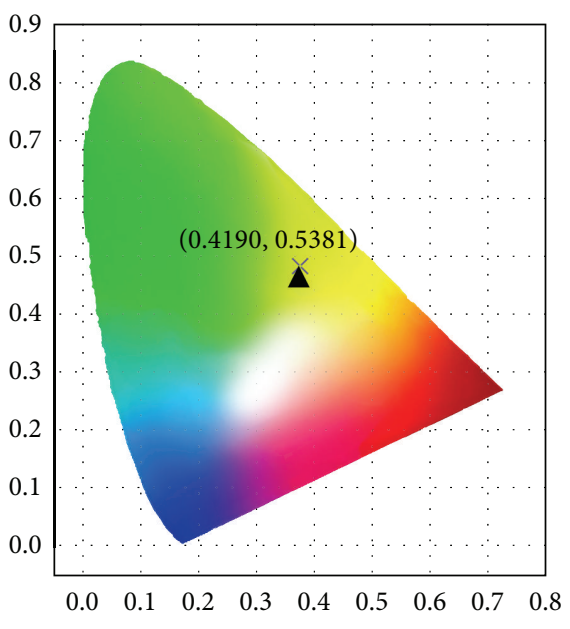

(d)

FIGURE 3: (a) UC spectra of $\mathrm{Lu}_{2} \mathrm{O}_{3}: \mathrm{Yb} / \mathrm{Er}$, (b) CIE chromaticity coordinates diagram of $\mathrm{Lu}_{2} \mathrm{O}_{3}: \mathrm{Yb} / \mathrm{Er}$, (c) UC spectra of $\mathrm{Lu}_{2} \mathrm{O}_{3}: \mathrm{Yb} / \mathrm{Ho}$, and (d) CIE chromaticity coordinates diagram of $\mathrm{Lu}_{2} \mathrm{O}_{3}: \mathrm{Yb} / \mathrm{Ho}$; the right insets of (a) and (c) are the corresponding digital photographs of $1 \mathrm{wt} \%$ water soluble of the samples.

The upconverted luminescence properties of as-prepared samples were well investigated under excitation of $980 \mathrm{~nm}$ laser diode. By changing the doped ions from Er to Ho, the upconversion emissions transform from eye-visible red to bright yellow light. Moreover, high pure red upconversion emission was obtained in $\mathrm{Yb} / \mathrm{Er}$ codoped sample, which is suitable for high contrast optical bioimaging with absence of autofluorescence owing to the low tissue absorption at red light area $(655 \mathrm{~nm})$.

\section{Acknowledgments}

This work was supported by the National Natural Science Foundation of China (no. 51102202), New Century Excellent
Talents in University (NCET-13-0787), Specialized Research Fund for the Doctoral Program of Higher Education of China (no. 20114301120006) and Hunan Provincial Natural Science Foundation of China (nos. 12JJ4056 and 13JJ1017), the Scientific Foundation of Ministry of Education (212119), and Scientific Research Fund of Hunan Provincial Education Department (13B062).

\section{References}

[1] E. Downing, L. Hesselink, J. Ralston, and R. Macfarlane, "A three-color, solid-state, three-dimensional display," Science, vol. 273, no. 5279, pp. 1185-1189, 1996.

[2] B. M. van der Ende, L. Aarts, and A. Meijerink, "Lanthanide ions as spectral converters for solar cells," Physical Chemistry 


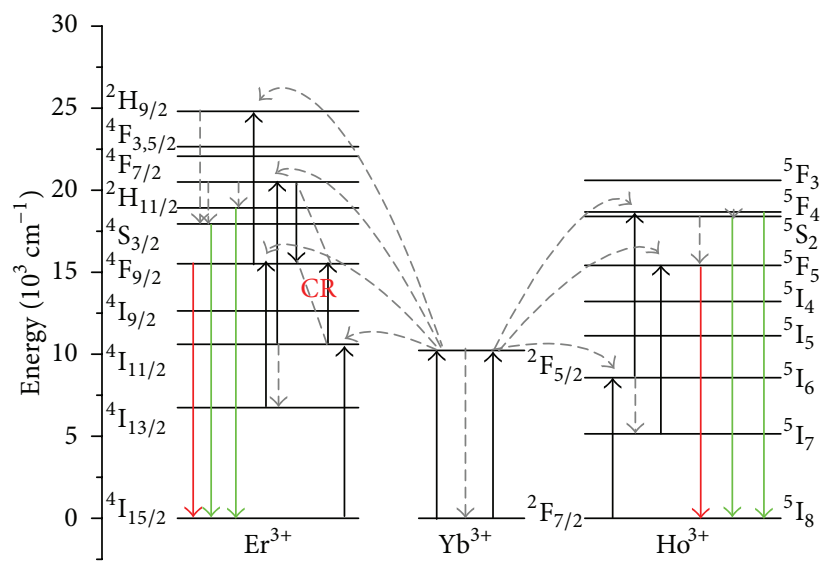

FIGURE 4: Schematic energy level diagrams of $\mathrm{Yb}^{3+}, \mathrm{Er}^{3+}$, and $\mathrm{Ho}^{3+}$ ions and proposed upconversion mechanism.

Chemical Physics, vol. 11, no. 47, pp. 11081-11095, 2009.

[3] G. F. Wang, Q. Peng, and Y. D. Li, "Lanthanide-doped nanocrystals: synthesis, optical-magnetic properties, and applications," Accounts of Chemical Research, vol. 44, no. 5, pp. 322-332, 2011.

[4] H. R. Liu, W. Lu, H. B. Wang et al., "Simultaneous synthesis and amine-functionalization of single-phase $\mathrm{BaYF}_{5}: \mathrm{Yb} / \mathrm{Er}$ nanoprobe for dual-modal in vivo upconversion fluorescence and long-lasting X-ray computed tomography imaging," Nanoscale, vol. 5, no. 13, pp. 6023-6029, 2013.

[5] N. Lewinski, V. Colvin, and R. Drezek, "Cytotoxicity of nanopartides," Small, vol. 4, no. 1, pp. 26-49, 2008.

[6] J. M. Klostranec and W. C. W. Chan, "Quantum dots in biological and biomedical research: recent progress and present challenges," Advanced Materials, vol. 18, no. 15, pp. 1953-1964, 2006.

[7] S. J. Zeng, M. K. Tsang, C. F. Chan, K. L. Wong, and J. H. Hao, "PEG modified $\mathrm{BaGdF}_{5}: \mathrm{Yb} / \mathrm{Er}$ nanoprobes for multi-modal upconversion fluorescent, in vivo X-ray computed tomography and biomagnetic imaging," Biomaterials, vol. 33, no. 36, pp. 9232-9238, 2012.

[8] F. Auzel, "Upconversion and anti-stokes processes with $\mathrm{f}$ and d ions in solids," Chemical Reviews, vol. 104, no. 1, pp. 139-174, 2004.

[9] S. J. Zeng, J. J. Xiao, Q. B. Yang, and J. H. Hao, "Bi-functional $\mathrm{NaLuF}_{4}: \mathrm{Gd}^{3+} / \mathrm{Yb}^{3+} / \mathrm{Tm}^{3+}$ nanocrystals: structure controlled synthesis, near-infrared upconversion emission and tunable magnetic properties," Journal of Materials Chemistry, vol. 22, no. 19, pp. 9870-9874, 2012.

[10] J. C. Boyer, F. Vetrone, L. A. Cuccia, and J. A. Capobianco, "Synthesis of colloidal upconverting $\mathrm{NaYF}_{4}$ nanocrystals doped with $\mathrm{Er}^{3+}, \mathrm{Yb}^{3+}$ and $\mathrm{Tm}^{3+}, \mathrm{Yb}^{3+}$ via thermal decomposition of lanthanide trifluoroacetate precursors," Journal of the American Chemical Society, vol. 128, no. 23, pp. 7444-7445, 2006.

[11] G. Z. Ren, S. J. Zeng, and J. H. Hao, “Tunable multicolor upconversion emissions and paramagnetic property of monodispersed bifunctional lanthanide-doped $\mathrm{NaGdF}_{4}$ nanorods," Journal of Physical Chemistry C, vol. 115, no. 41, pp. 20141-20147, 2011.

[12] F. Wang and X. G. Liu, "Recent advances in the chemistry of lanthanide-doped upconversion nanocrystals," Chemical Society Reviews, vol. 38, no. 4, pp. 976-989, 2009.

[13] S. J. Zeng, G. Z. Ren, C. F. Xu, and Q. B. Yang, "Modifying crystal phase, shape, size, optical and magnetic properties of monodispersed multifunctional $\mathrm{NaYbF}_{4}$ nanocrystals through lanthanide doping," CrystEngComm, vol. 13, no. 12, pp. 42764281, 2011.

[14] J. Trojan-Piegza, E. Zych, D. Hreniak, W. Stręk, and L. Kępiński, "Structural and spectroscopic characterization of $\mathrm{Lu}_{2} \mathrm{O}_{3}: \mathrm{Eu}$ nanocrystalline spherical particles," Journal of Physics Condensed Matter, vol. 16, no. 39, pp. 6983-6994, 2004.

[15] J. C. Boyer, F. Vetrone, J. A. Capobianco, A. Speghini, and M. Bettinelli, "Variation of fluorescence lifetimes and judd-ofelt parameters between $\mathrm{Eu}^{3+}$ doped bulk and nanocrystalline cubic $\mathrm{Lu}_{2} \mathrm{O}_{3}$, Journal of Physical Chemistry B, vol. 108, no. 52, pp. 20137-20143, 2004.

[16] R. D. Shannon, "Revised effective ionic radii and systematic studies of interatomic distances in halides and chalcogenides," Acta Crystallographica A, vol. 32, no. 5, pp. 751-767, 1976.

[17] P. Rambaldi, R. Moncorgé, J. P. Wolf, C. Pédrini, and J. Y. Gesland, "Efficient and stable pulsed laser operation of Ce:LiLuF around 308 nm," Optics Communications, vol. 146, no. 1-6, pp. 163-166, 1998.

[18] V. Sudesh and K. Asai, "Spectroscopic and diode-pumped-laser properties of Tm,Ho:YLF; Tm,Ho:LuLF; and Tm,Ho:LuAG crystals: a comparative study," Journal of the Optical Society of America B, vol. 20, no. 9, pp. 1829-1837, 2003.

[19] C. Maunier, J. L. Doualan, R. Moncorgé, A. Speghini, M. Bettinelli, and E. Cavalli, "Growth, spectroscopic characterization, and laser performance of $\mathrm{Nd}: \mathrm{LuVO}_{4}$, a new infrared laser material that is suitable for diode pumping," Journal of the Optical Society of America B, vol. 19, no. 8, pp. 1794-1800, 2002.

[20] H. J. Qiu, Y. Shi, J. J. Xie, J. Xie, L. L. Zhang, and F. F. $\mathrm{Xu}$, "Hydrothermal route to $\mathrm{Eu}$ doped $\mathrm{LuO}(\mathrm{OH})$ and $\mathrm{Lu}_{2} \mathrm{O}_{3}$ nanorods," Science China Technological Sciences, vol. 53, no. 6, pp. 1576-1582, 2010.

[21] H. Guo, M. Yin, N. Dong, M. Xu, L. R. Lou, and W. P. Zhang, "Effect of heat-treatment temperature on the luminescent properties of $\mathrm{Lu}_{2} \mathrm{O}_{3}:$ Eu film prepared by Pechini sol-gel method," Applied Surface Science, vol. 243, no. 1-4, pp. 245-250, 2005.

[22] P. P. Yang, S. L. Gai, Y. C. Liu, W. X. Wang, C. X. Li, and J. Lin, "Uniform hollow $\mathrm{Lu}_{2} \mathrm{O}_{3}: \mathrm{Ln}\left(\mathrm{Ln}=\mathrm{Eu}^{3+} / \mathrm{Tb}^{3+}\right)$ spheres: facile synthesis and luminescent properties," Inorganic Chemistry, vol. 50, no. 6, pp. 2182-2190, 2011.

[23] N. Niu, P. P. Yang, F. He et al., "Tunable multicolor and bright white emission of one-dimensional $\mathrm{NaLuF}_{4}: \mathrm{Yb}^{3+}, \mathrm{Ln}^{3+}$ 
( $\mathrm{Ln}=\mathrm{Er}, \mathrm{Tm}, \mathrm{Ho}, \mathrm{Er} / \mathrm{Tm}, \mathrm{Tm} / \mathrm{Ho})$ microstructures," Journal of Materials Chemistry, vol. 22, no. 21, pp. 10889-10899, 2012.

[24] E. W. Barrera, M. C. Pujol, F. Díaz et al., "Emission properties of hydrothermal $\mathrm{Yb}^{3+}, \mathrm{Er}^{3+}$ and $\mathrm{Yb}^{3+}, \mathrm{Tm}^{3+}$-codoped $\mathrm{Lu}_{2} \mathrm{O}_{3}$ nanorods: upconversion, cathodoluminescence and assessment of waveguide behavior," Nanotechnology, vol. 22, no. 7, Article ID 075205, 2011.

[25] Y. P. Li, J. H. Zhang, Y. S. Luo, X. Zhang, Z. D. Hao, and X. J. Wang, "Color control and white light generation of upconversion luminescence by operating dopant concentrations and pump densities in $\mathrm{Yb}^{3+}, \mathrm{Er}^{3+}$ and $\mathrm{Tm}^{3+}$ tri-doped $\mathrm{Lu}_{2} \mathrm{O}_{3}$ nanocrystals," Journal of Materials Chemistry, vol. 21, no. 9, pp. 2895-2900, 2011.

[26] X. Wang and Y. D. Li, "Rare-earth-compound nanowires, nanotubes, and fullerene-like nanoparticles: synthesis, characterization, and properties," Chemistry, vol. 9, no. 22, pp. 56275635, 2003. 

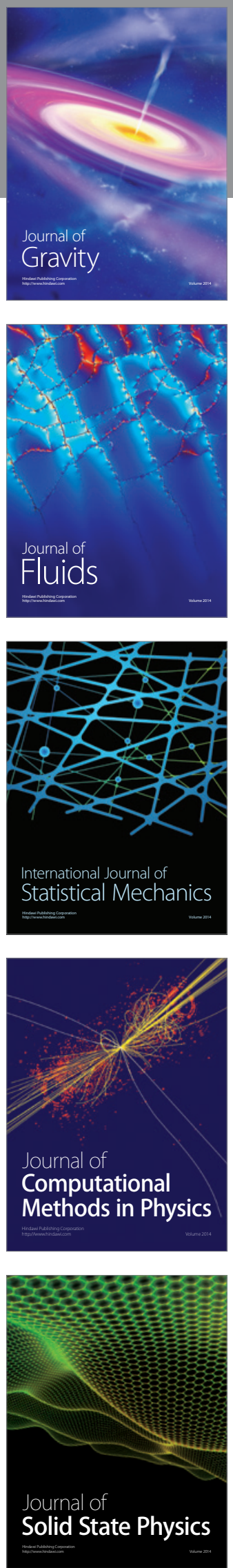

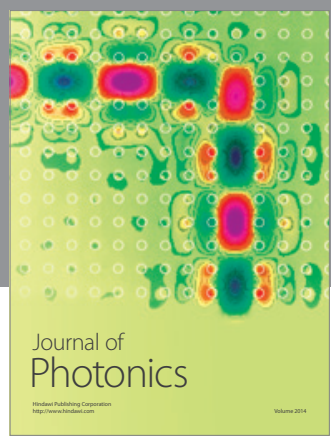

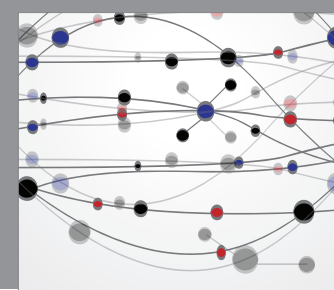

The Scientific World Journal

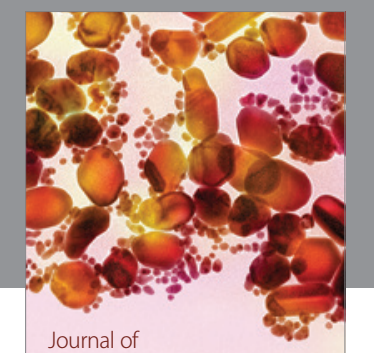

Soft Matter
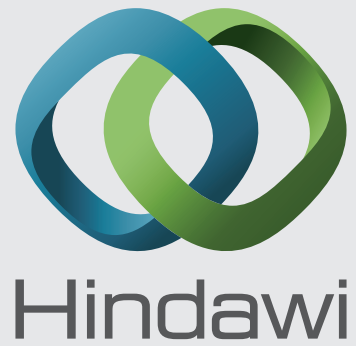

Submit your manuscripts at

http://www.hindawi.com
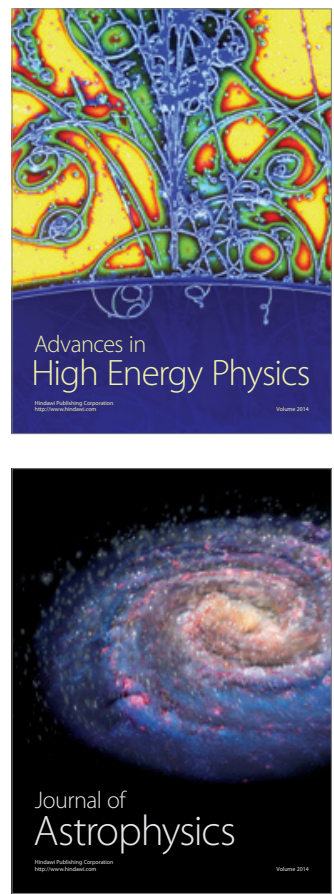
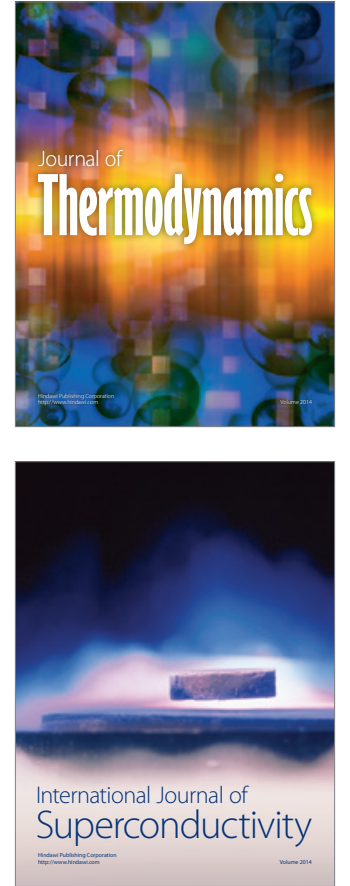
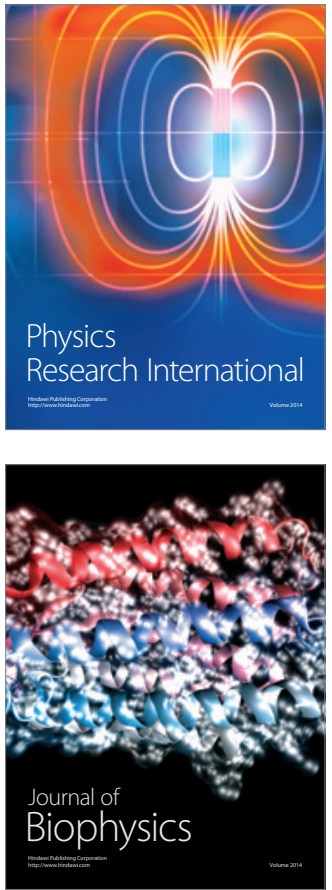
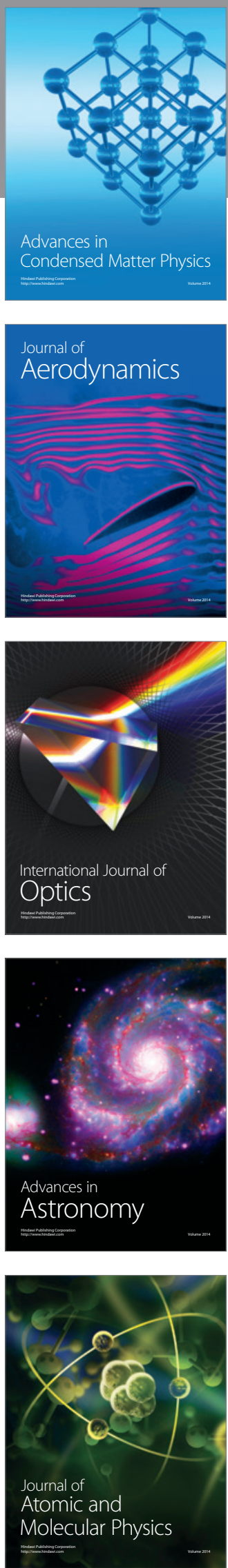